\title{
A RESPONSABILIDADE SOCIAL EMPRESARIAL E O ESTADO uma aliança para o desenvolvimento sustentável
}

\author{
Elizabeth de Melo Rico
}

\begin{abstract}
Resumo: Este artigo contextualiza historicamente o surgimento da Responsabilidade Social Empresarial no Brasil. Analisa suas propostas e as controvérsias, bem como suas relações e parcerias com o Estado e a sociedade civil face ao enfrentamento da questão social, tendo como perspectiva o desenvolvimento econômico, social viável e ambientalmente sustentável

Palavras-chave: responsabilidade social empresarial; políticas públicas; desenvolvimento sustentável.
\end{abstract}

Abstract: This paper brings into context the emerging of the Corporate Social Responsability in Brazil. It analyses its proposals and controversies, as well as its relationships and paternships with both the State and the civil society in face of the social matter within a development process that must be socially and economically possible and environmentally sustainable.

Key words: corporate social responsability; public politics; sustainable development.

$\mathrm{O}$ Instituto Ethos ${ }^{1}$ conceitua responsabilidade social empresarial como "a forma de gestão que se define pela relação ética e transparente da empresa com todos os públicos com os quais ela se relaciona e pelo estabelecimento de metas empresariais compatíveis com o desenvolvimento sustentável da sociedade, preservando recursos ambientais e culturais para gerações futuras, respeitando a diversidade e a redução das desigualdades sociais" (INSTITUTO ETHOS, 2004).

Em especial, nas últimas duas décadas vem aumentando o interesse e conseqüente investimento do empresariado brasileiro na área social. Discutem-se temas sobre o gerenciamento social, implementação de projetos sociais comunitários, o empresário ético e a responsabilidade social.

Na compreensão dos institutos, fundações, associações empresariais que vêm buscando assumir uma gestão socialmente responsável nos negócios, a responsabilidade social empresarial é uma forma de conduzir as ações organizacionais pautada em valores éticos que visem integrar todos os protagonistas de suas relações: clientes, fornecedores, consumidores, comunidade local, governo (público externo) e direção, gerência e funcionários (público interno), ou seja, todos aqueles que são diretamente ou não afetados por suas atividades, contribuindo para a construção de uma sociedade que promova a igualdade de oportunidades e a inclusão social no país. As empresas, adotando um comportamento socialmente responsável, são poderosos agentes de mudança ao assumirem parcerias com o Estado e a sociedade civil, na construção de um mundo economicamente mais próspero e socialmente mais justo.

É o caso de se perguntar quais são os motivos que têm impulsionado segmentos do empresariado brasileiro a adotar a postura de responsabilidade social empresarial.

Historicamente, a filantropia e a assistência não fizeram parte da cultura empresarial brasileira. Segundo Rico (2001), até o início do nosso processo de industrialização e mesmo a partir dele as ações sociais empresariais foram heterogêneas, pontuais, dependentes e tuteladas pelo Estado. Inexistiam ações assistenciais sistemáticas aos pobres, a partir de medidas tomadas pelo Estado. A prática des- 
sas ações era uma forma de os ricos ascenderem aos valores aristocráticos, pela prática do "bem" através de esmolas (SPOSATI, 1988). O Estado brasileiro limitava-se a reconhecer as ações assistenciais praticadas pelas irmandades, atribuindo um papel diferenciado à Igreja.

A assistência social privada, agraciada como benesses estatais, era a forma transfigurada com que o poder público insinuava assistir à miséria [...] sustentada pela Irmandade de Misericórdia, forma combinada do público e privado, do religioso e leigo [...] (SPOSATI, 1988, p. 85).

Tal postura assistencialista, via de regra, usada como sinônimo de filantropia, consiste na prestação de um auxílio material ou financeiro destinado a atender uma problemática imediata tal como alimentação, saúde, habitação, dentre outras. A prática clientelista envolve uma relação de dominação e dependência estabelecida entre quem detém o poder sobre os serviços sociais e os usuários.

Rico (2001) acrescenta que as ações heterogêneas e pontuais da filantropia privada explicam-se, historicamente, pelo papel que a burguesia brasileira desempenhou no processo de acumulação capitalista, ou seja, dependente e tutelada pelo Estado, demonstrando desinteresse por constituir uma identidade de classe dominante no processo de constituição de um capitalismo nacional e na contribuição de um desenvolvimento econômico, político e social.

A proposta do empresariado brasileiro não era pautada em princípios liberais, na defesa da livre iniciativa e do livre mercado, pois sua opção deu suporte à intervenção estatal em várias áreas da economia, em especial naquelas em que o setor privado não tinha interesse em atuar ou em áreas que exigem um longo prazo de investimento, como é o caso dos setores da infra-estrutura (BOSCHI, 1990).

Tal postura do empresariado, desvinculada de uma identidade de classe burguesa nacionalista, tutelada e dependente do Estado, usufruiu, obviamente, de suas benesses, praticamente até o regime militar.

A partir do processo de transição democrática, nos anos 70 e especialmente a partir da década de 80 , é que se pode identificar uma ação social empresarial com a expectativa de participação no desenvolvimento social do país.

Nos anos 80, a intensificação do processo tecnológico - acrescido do surgimento das sofisticadas tecnologias de informação, da eliminação das fronteiras dos Estados nacionais, da socialização dos valores liberais de mercado e da polarização nacional-global - se associou ao processo que se denominou globalização econômica. ${ }^{2}$

A internacionalização da economia e a conseqüente abertura para um mercado global implementaram de for- ma rigorosa o novo modo de ser das relações econômicas. O capital empresarial não está vinculado a um Estado-nação enquanto lócus de aplicação do mesmo.

Diante dessa nova organização empresarial global, as organizações privadas possuem uma nova diretriz nos rumos da obtenção do lucro, pois simplesmente as vantagens oferecidas em relação a valores (preços) não estão sendo suficientes para a obtenção de um mercado consumidor. Cada vez mais a qualidade do produto está relacionada à relação da empresa com a sociedade e seu comportamento ético e esses fatores determinam o comportamento dos consumidores (PAES, 2003, p. 25).

Segundo Mifano (2002), a responsabilidade social das organizações surgiu num contexto no qual há uma crise mundial de confiança nas empresas. Para tanto, as organizações empresariais começaram a promover um discurso politicamente correto, pautado na ética, implementando ações sociais que podem significar ganhos em condições de qualidade de vida e trabalho para a classe trabalhadora ou, simplesmente, podem se tornar um mero discurso de marketing empresarial desvinculado de uma prática socialmente responsável.

Uma das conseqüências de um projeto social bem-sucedido é o seu reconhecimento institucional, comunitário e social; em outras palavras, a construção de uma imagem positiva por meio de um investimento que contribuiu diretamente para a melhoria da vida comunitária, provocando impactos positivos na comunidade. As organizações empresariais têm como tendência financiar atividades, dando preferência àquelas relacionadas com os bens e serviços que produzem ou comercializam. Hoje há uma preocupação no sentido de avaliar até que ponto as práticas de responsabilidade social de uma empresa são percebidas pelo consumidor e reforçam a sua marca e como desenvolver um planejamento integrado no qual as ações sociais sejam incorporadas à valorização da marca da empresa.

Além disso, é preciso considerar que pesquisas feitas nos Estados Unidos apontaram números impressionantes: 68\% dos jovens optariam por trabalhar em alguma empresa que tivesse algum projeto social e nada menos que $76 \%$ dos consumidores preferem marcas e produtos envolvidos com algum tipo de ação social. Os dirigentes empresariais perceberam que é necessário fazer com que as pessoas gostem da empresa, se identifiquem com a sua marca e tenham prazer em trabalhar no seu negócio. Os profissionais mais qualificados e talentosos preferem trabalhar em empresas que respeitem os direitos, a segurança e a qualidade de vida de seus funcionários. Todo dirigente empresarial sabe que a 
qualidade e a motivação das pessoas que trabalham na empresa são fundamentais para o seu progresso. Outras pesquisas estão mostrando que os consumidores, ao escolherem um produto ou serviço, estão dando cada vez mais importância à postura da empresa em relação ao meio ambiente, ao respeito que ela demonstra às leis e aos direitos humanos e aos investimentos que ela faz para melhorar a vida da comunidade (VASSALO, 1999).

Portanto, trata-se de uma questão estratégica o investimento na área social, pois as empresas ao serem reconhecidas como socialmente responsáveis tendem a conseguir diferenciais de competitividade e uma vez tendo a imagem valorizada, podem aumentar a motivação dos funcionários no trabalho e atrair um número maior de parceiros dispostos a colaborar com a causa social. Conseqüentemente, a empresa consegue melhorar sua produtividade. A empresa utiliza várias estratégias para vender e tornar pública a imagem dos seus produtos (marketing, promoção, publicidade). Os custos dessas atividades, incluindo os investimentos em ações sociais, são repassados ao preço final do produto. Portanto, são mecanismos comerciais com objetivos econômicos que não oneram a empresa.

Será a partir do cenário dos anos 90 a consolidação dos investimentos sociais empresariais. ${ }^{3}$ A preocupação com benemerência e ações pontuais cede lugar a investimentos que possibilitem retorno na aplicação de recursos em programas sociais. Aliás, o empresariado investe usando seus próprios conhecimentos na administração dos seus negócios: gestão, planejamento estratégico, planejamento financeiro, estratégias de marketing e capacitação de recursos. Preocupam-se com a profissionalização das entidades sociais, no intuito de maximizar resultados. É preciso saber mensurar, do ponto de vista qualitativo e quantitativo, aquilo que se obteve através da implementação de um programa social. Sem criar estratégias sobre as várias dimensões do processo de avaliação, não é possível calcular os impactos de um programa social e mesmo saber se os seus objetivos foram atingidos, por exemplo: quantas pessoas foram atendidas, como perceberam esse atendimento, quais os resultados do projeto, se houve continuidade e multiplicação do mesmo, que tipo de retorno - em termos de imagem e confiança - a empresa vem conseguindo, dentre outros.

As transformações derivadas do processo de globalização, contraditoriamente,

geraram um aumento de oportunidades para uma parcela significativa de cidadãos, mas, por outro lado, influenciaram no crescimento desordenado da pobreza e da desigualdade, na insegurança econômica, no deslocamento social e na degradação ambiental, para outros. A obtenção do crescimento econômico nesse novo mundo, sem abandonar as metas de redução da pobreza, da coesão social e da sustentabilidade ambiental, torna-se o principal desafio para quase todos governos, neste início de século (RICO, 2002, p. b-8).

Uma das principais conseqüências do processo de globalização foi a reconfiguração das relações de trabalho: enxugamento dos postos de trabalho, desemprego e aumento do trabalho informal.

Para se ter uma noção da gravidade do problema segundo pesquisas da Fundação Sistema Estadual de Análise de Dados - Seade e do Departamento Intersindical de Estatística e Estudos Sócio-Econômicos - Dieese, a taxa de desemprego na Região Metropolitana de São Paulo subiu de 19,1\% em janeiro/2004 para 19,8\% em fevereiro. É a maior taxa de desemprego desde 1985 quando começou a pesquisa. São aproximadamente 1,926 milhão de pessoas desempregadas e é importante esclarecer que os dados da Fundação Seade e do Dieese abrangem não só o mercado formal, mas também o informal, cujas informações são obtidas mediante entrevistas em domicílio. Nesse sentido, diferem-se dos números que foram apresentados pela Federação das Indústrias do Estado de São Paulo - Fiesp e pelo Ministério do Trabalho, que são coletados na indústria e junto aos portadores de carteira assinada (FOLHA DE S.PAULO, 2004, p. B4).

A responsabilidade social empresarial passa assim pela compreensão do modelo político-econômico instaurado a partir do processo de globalização, pelos problemas sociais estruturais decorrentes, pela necessidade da reforma do Estado (diminuição dos investimentos em políticas públicas) e pelas pressões cada vez mais freqüentes, da sociedade civil.

\section{RESPONSABILIDADE SOCIAL EMPRESARIAL E DEMOCRACIA}

Destaque-se que a responsabilidade social empresarial está associada de forma intrínseca a dois fatores, que definem a essência da sua prática: ética e transparência na gestão de negócios.

Estes fatores concretizam-se no cotidiano das organizações privadas. Há empresas que ofertam produtos e serviços de reconhecida qualidade para seus consumidores. Todavia, se no desenvolvimento de suas atividades utilizam a prática de jogar dejetos nos rios, não estarão sendo éticas nas suas relações com a sociedade, revelando uma 
atividade negligente em relação ao meio ambiente. Rios poluídos geram doenças e enormes gastos com a saúde curativa, com tratamento de água e esgoto (saneamento básico), prejuízos em atividades como pesca ou turismo, etc. As prefeituras terão de proceder a recuperação da água poluída com verbas provenientes de impostos que arrecadam do cidadão, ou seja, o cidadão paga duas vezes por aquilo que não provocou: quando compra o produto $\mathrm{e}$ quando o seu dinheiro é destinado à recuperação da água poluída. O resultado prático, segundo Dowbor (2001), é uma sociedade que, além de perder dinheiro, vai perdendo o que lhe é essencial: a sua qualidade de vida.

Nesse sentido, o ser ético nos negócios supõe que as decisões de interesse de determinada empresa respeitem os direitos, os valores e os interesses de todos os indivíduos que de uma forma ou de outra são por ela afetados (INSTITUTO ETHOS, 2003).

Transparência é o outro conceito central da responsabilidade social empresarial que caminha ao lado da atitude ética. Ser transparente é atender às expectativas sociais, mantendo a coerência entre o discurso e a prática e não sonegando informações importantes sobre seus produtos e serviços.

Um dos instrumentos notáveis que incentiva a atitude de comunicação transparente da empresa com os públicos com os quais se relaciona é o balanço social.

O balanço social é um documento publicado anualmente, reunindo um conjunto de informações sobre as atividades econômicas, ambientais e sociais desenvolvidas pela empresa que apresenta os seus principais compromissos públicos, as metas para o futuro, os problemas que imagina enfrentar e os possíveis parceiros com quem pretende trabalhar para equacionar os desafios previstos. Por meio do balanço social, a empresa mostra o que fez pelos empregados e seus dependentes e pela população sobre quem exerce influência direta. É "um instrumento pelo qual a empresa divulga o investimento em projetos e/ou ações sob a ótica da responsabilidade social" (MENEGASSO, 2002, p. 8).

Embora não seja obrigatória a divulgação do balanço social no Brasil, algumas instituições como a Fundação Instituto de Desenvolvimento Empresarial e Social - Fides e o Instituto Brasileiro de Análises Sociais - Ibase vêm desenvolvendo modelos de balanço social com o objetivo de incentivar e facilitar a sua publicação pelas empresas. O próprio Ibase, em 1997, divulgou um modelo baseado na Lei n. 3.116.

Reconhecer publicamente os esforços da responsabilidade social desenvolvidos por empresas é o objetivo do Selo Empresa Cidadã, que em 2003, em sua $3^{\mathrm{a}}$ edição, premiou 28 organizações privadas. Essa iniciativa foi criada a partir da Resolução Legislativa n. 05/98, de autoria da então vereadora Aldaíza Sposati.

O Selo Empresa Cidadã é concedido a organizações que contribuem para o desenvolvimento da comunidade e que adotam um comportamento ético na busca da consolidação da cidadania. Este prêmio é concedido às empresas que se destacam nas seguintes áreas do balanço social: meio ambiente, ambiente de trabalho, ambiente social e qualidade de vida, ambiente urbano, qualidade dos produtos e serviços, desenvolvimento dos direitos humanos e difusão da conduta de responsabilidade social. É através do balanço social que as empresas tornam públicos os seus compromissos e condutas de responsabilidade social, difundindo o vínculo entre a ética e o processo produtivo. O balanço social é um instrumento de controle sobre as obrigações das empresas em relação a todos os seus atores: empregados, clientes, fornecedores financiadores, comunidades (governos locais e nacionais, além daquelas obrigações relacionadas aos proprietários).

As empresas que recebem o Selo Empresa Cidadã adquirem algumas vantagens: podem utilizá-lo em produtos, embalagens, propagandas e correspondências. Conseqüentemente, passam a ser reconhecidas pelo compromisso com a qualidade de vida, eqüidade e desenvolvimento dos funcionários e sua família, pela comunidade e preservação do meio ambiente (CIEE, 1999).

Salienta-se que são segmentos do empresariado que defendem a idéia da elaboração e da divulgação do balanço social como um instrumento de demonstração do seu envolvimento social junto à sociedade, considerando inclusive que o mesmo é um dos indicadores da responsabilidade social empresarial.

Podem ser relacionados alguns institutos e associações empresariais que vêm defendendo a publicação do balanço social junto a seus associados. O Instituto Ethos possui inclusive uma publicação sobre esse tema (Guia de Elaboração do Balanço Social). Importante mencionar o Grupo de Institutos, Fundações e Empresas - Gife ${ }^{4}$ por ser a primeira associação da América do Sul, fundada em 1995, que reúne organizações de origem privada que financiam ou executam projetos sociais, ambientais e culturais de interesse público.

Hoje, o Gife possui um universo de 69 associados que destinam mais de $R \$ 700$ milhões por ano a iniciativas que buscam a melhoria das condições de vida dos brasileiros, implementando ou apoiando ações nas áreas de educação, cultura, saúde, meio ambiente, desenvolvimento comunitário, voluntariado, entre outras. 
Todavia depara-se com fenômenos complexos ao procurar desvelar o significado da responsabilidade social empresarial. Iniciaremos nossas indagações tomando como exemplo a primeira associação de empresários fundada no Brasil, sendo igualmente a primeira da América do Sul: o Gife. Desde sua criação, seja pela implementação de projetos, realização de pesquisas, publicação sistemática de artigos, livros e documentos, seja pela sua participação em fóruns nacionais e internacionais (dentre outras atividades), o Gife conquistou ao longo dos seus dez anos de existência a imagem pública de uma associação que atua em parceria com outras empresas, ONGs (organizações não-governamentais), instituições da sociedade civil e com o Estado, tendo o compromisso de inovar e contribuir para o desenvolvimento sustentável do país. Os projetos desenvolvidos pela rede de seus associados são considerados modelos de investimento social privado. A maioria dessas ações pode ser multiplicada ou inspirar outras organizações privadas a atuarem na busca de soluções para as desigualdades sociais existentes em nosso país (GIFE, 2001).

Em 2001, o Gife publicou um censo, apresentando os resultados de um amplo levantamento sobre a origem, natureza, formas de atuação e abrangência das suas 48 organizações afiliadas na época (GIFE, 2001).

Resultante desse censo, encontram-se destacadas aqui apenas duas tabelas relacionadas à política de difusão de informações e prestação de contas. Apesar da ênfase que vem sendo dada para que as empresas assumam a transparência dos seus negócios, incluindo os investimentos sociais, e publiquem o seu balanço social, observa-se na Tabela 1 (Publicação do Balanço Contábil) que apenas 52,1\% das empresas associadas divulgam os dados relativos ao balanço contábil.

TABELA 1

Publicação de Balanço Contábil das Empresas Associadas ao Gife

Brasil - 2001

\begin{tabular}{lcr}
\hline Situação & Nos Absolutos & $\%$ \\
\hline Total & 48 & 100,0 \\
Sim & 25 & 52,1 \\
Não & 20 & 41,7 \\
NS/NR & 3 & 6,2 \\
\hline
\end{tabular}

Fonte: Censo Gife Investimento Social Privado.

A Tabela 2 trata das instâncias junto às quais é feita prestação de contas dos recursos. Novamente, observa-se a mesma tendência: apenas $56,2 \%$ das associadas comunicam seus resultados às empresas mantenedoras e 50\% divulgam ao público interno da organização/empresa. Ao nosso ver, esses dados contrariam um dos mais importantes indicadores da responsabilidade social empresarial, a comunicação com os públicos com os quais se relaciona, acrescentando-se ainda que apenas 39,6\% das associadas prestam contas aos financiadores externos, $35,4 \%$ ao público externo e $25 \%$ às entidades apoiadas pela organização.

TABELA 2

Instâncias Junto às Quais é Feita Prestação de Contas dos Recursos e das Atividades Desenvolvidas pelas Empresas Associadas ao Gife Brasil - 2001

\begin{tabular}{lcc}
\hline Instância & Nos Absolutos & $\%$ \\
\hline Empresa mantenedora & 27 & 56,2 \\
Público interno à organização/empresa & 24 & 50,0 \\
Financiadores externos & 19 & 39,6 \\
Público externo em geral & 17 & 35,4 \\
Entidades apoiadas pela organização & 12 & 25,0 \\
Empresa matriz/holding & 4 & 8,3 \\
NS/NR & 2 & 4,2 \\
\hline
\end{tabular}

Fonte: Censo Gife Investimento Social Privado.

Nota: Questões com alternativas múltiplas. Total de 48 associados. Os percentuais foram calculados levando-se em consideração o número de respostas em cada alternativa neste universo de 48 associados.

Estes dados demonstram uma certa resistência a expor de forma transparente o que fazemos, o que não conseguimos fazer e porquê isso acontece. Em outras palavras, tornar público o compromisso que nos dispomos a assumir.

Estamos nos referindo, neste momento, a uma das principais e mais representativas associações empresariais, o Gife, cuja atuação tem por objetivo "buscar soluções para a superação das desigualdades sociais brasileiras, tendo como objetivo estratégico influenciar as políticas públicas". Observa-se que a comunicação das suas afiliadas com os seus diversos públicos é um processo fácil. Nossas observações não estão apenas direcionadas ao Gife. Ele é apenas um dos exemplos (uma associação representativa dentre muitas) que demonstra o quanto é difícil, neste país, tornar públicos e transparentes os compromissos assumidos, adotando efetivamente uma postura de comprometimento com o desenvolvimento sustentável.

Os caminhos da construção da sociedade democrática perpassam pela constituição de relações éticas e transparentes entre Estado, mercado e sociedade civil e pela presença e o lugar que ocupam as associações e corporações privadas.

A democracia é condicionada pela atual realidade mundial e nacional, refletindo que para além de sua natureza política institucional, ainda frágil, deve avançar nas esferas econômica e social. A democracia se concretiza 
no cotidiano, exigindo regras de convivência, respeito, justiça social, direitos humanos, dissensos e consensos e gestão estratégica. O conflito lhe é inerente e, portanto, deve-se estar sempre atento à busca de negociações, apresentando alternativas que envolvam os diversos segmentos da sociedade.

Nesse sentido é que a nossa história político-econômica, acrescida de uma tradição cultural autoritária, clientelista dos nossos governantes e do nosso empresariado, da pouca convivência com o processo de democratização (instaurado após a Ditadura Militar) ao pretender conquistar o desenvolvimento sustentável, só poderia defrontar-se com tais contradições.

Compreende-se que para segmentos do empresariado ${ }^{5}$ envolvidos com os princípios da responsabilidade social empresarial e que procuram implementar projetos sociais, mesmo que incipientes diante da crise social em que está mergulhado o Brasil, é um grande desafio assumir na prática uma nova gestão empresarial.

\section{UMA ALIANÇA VIÁVEL PARA O ENFRENTAMENTO DA QUESTÃO SOCIAL?}

A nova politica de desenvolvimento deve se basear na busca incansável da transformação produtiva com eqüidade social. A nova ética é a da co-responsabilidade dos grandes setores da vida brasileira (governo, mundo empresarial e terceiro setor) no enfrentamento das desigualdades sociais intoleráveis (SENNA, 2001, p. 11).

Viviane Senna é a responsável por um dos institutos que mais tem se destacado nas questões da implementação de projetos sociais aliada aos princípios da responsabilidade social empresarial: Instituto Ayrton Senna.

Nesta fala destaca-se o seu propósito dirigido ao "enfrentamento das desigualdades sociais intoleráveis", ou seja, a questão social no Brasil de hoje.

Esta questão é aqui compreendida

como um processo de exclusão social que não é passageiro, mas ao contrário, amplia-se e se reproduz [...], perpetuando-se no âmbito dos diferentes niveis da prática social (NASSER, 2000, p. 305).

Esse processo reflete-se sob a forma de sucessivas perdas na totalidade da vida dos indivíduos, enquanto seres sociais. Entende-se que a centralidade do processo de exclusão social vincula-se ao conjunto de problemas políticos, sociais e econômicos intrínsecos à sociedade capitalista. O processo de exclusão social supõe o conceito de pobreza, expresso através de um parâmetro monetário vinculado ao custo de atender às necessidades básicas no âmbito privado, ou seja, as despesas necessárias para atingir o mínimo de bem-estar considerado aceitável em determinada região do país. Outros componentes que são incluídos no conceito de pobreza envolvem

outros aspectos de condição de vida não imediata ou diretamente vinculadas à renda corrente - como condições de moradia e acesso a serviços públicos básicos (ROCHA, 2001, p. 72).

Sendo a pobreza um fenômeno associado a várias causas inter-relacionadas, tais como baixo nível de escolaridade, crescente expansão das atividades informais no mercado de trabalho, redução dos postos de trabalho e desemprego, é imprescindível destacar que a incidência da pobreza absoluta no Brasil está indissoluvelmente associada à forte desigualdade na distribuição de renda.

Conforme dados publicados na Folha de S.Paulo, em 2/04/2004, 2,4\% das famílias detêm $33 \%$ da riqueza produzida no país, proporção que vem aumentando desde a década de 80 (quando perfaziam um total de 1,8\%), passando a concentrar mais riqueza. ${ }^{6}$ As famílias ricas, em 2000 , referem-se às que tinham renda mensal superior a $\mathrm{R} \$ 10.982$, em valores de hoje.

No Gráfico 1 observa-se que a economia brasileira vem decrescendo ano a ano. Em 2003, perdeu três posições no ranking das maiores do mundo, ficando em $15^{\circ}$ lugar, com um Produto Interno Bruto - PIB de US\$ 493 bilhões, enquanto em 2002 ocupava a $12^{\mathrm{a}}$ posição, com um PIB de US\$ 459 bilhões.

Considerando-se que em 2000 era a $10^{\mathrm{a}}$ economia do mundo, com uma renda per capita de R\$ 6.056, mas já apresentando a $6^{\mathrm{a}}$ maior concentração de renda do mundo, entende-se que, hoje, o fato de o Brasil apresentar a $4^{\mathrm{a}}$ maior concentração de renda, por si só, leva a compreender a trágica crise social do país ou "as desigualdades sociais intoleráveis", segundo Senna.

O Brasil, como um dos países ao mesmo tempo subdesenvolvido e industrializado, guarda como característica fundamental a convivência com um capitalismo moderno marcado pela extrema concentração de renda, ao lado de um capitalismo predatório que produz e reproduz de forma selvagem e impune profundas desigualdades sociais (SPOSATI, 1995, p. 27).

A questão dos rumos definidos pela política econômica brasileira adotada (inserção no modelo de integração ao capital internacional sob a perspectiva de uma política 
neoliberal) fez com que o Estado brasileiro assumisse uma postura voltada, em grande parte, para a estabilidade econômica (entendendo-se a estabilidade da moeda) e deixando de investir cada vez mais em programas sociais, o que, conseqüentemente, tem acirrado as desigualdades sociais.

Nessa "nova" configuração de Estado, surge uma liberação das competências do mesmo, tornando-o livre de suas obrigações sociais com seus direitos e deveres. $\mathrm{Na}$ concepção do Estado Mínimo há uma conseqüente retração dos investimentos em políticas públicas e sociais, descentralização dos projetos sociais e privatização de alguns serviços sociais básicos. Neste sentido cria-se um espaço para as organizações e instituições da sociedade civil e as fundações empresariais atuarem junto à problemática social, desencadeada por uma crise sociopolíticaeconômica, sem precedentes na sociedade brasileira.

Todavia, é preciso compreender que esses investimentos empresariais estão ocorrendo num contexto político, econômico e social que afetou diretamente os negócios das empresas. Se os governos não têm assumido suas responsabilidades, para garantir o mínimo social necessário para todo o cidadão, abre-se um espaço público no qual organizações comunitárias, entidades assistenciais, ONGs (organizações não-governamentais) e fundações empresariais começam a buscar formas de reduzir a pobreza e fortalecer a democracia nas sociedades subdesenvolvidas. As empre- sas controlam os recursos financeiros gerenciais essenciais para a execução de programas públicos eficazes e atividades comunitárias. Por outro lado, uma política pública bem formulada e a estabilidade social são colunas vitais para sustentar as economias viáveis das empresas. Pode-se concluir, assim, que existem razões para formações de alianças entre o setor público e o privado que garantam a sobrevivência da política econômica globalizada.

Assinale-se que sob a bandeira da responsabilidade social empresarial delineia-se um espaço contraditório de relações sociais, no qual os interesses e necessidades vão se constituindo em demandas, na medida em que são apropriados pelas organizações e se institucionalizam como resposta.

Guimarães (1999) destaca que as parcerias são hoje compreendidas como fundamentais no enfrentamento da exclusão social, na medida em que possam agregar experiências inovadoras que sirvam de referência para a elaboração das políticas sociais. Acrescenta que, para o estabelecimento de parcerias, é fundamental a conservação da identidade dos parceiros. Cita, por exemplo, que a educação é um direito do cidadão para uma participação plena na vida em sociedade, mas é uma responsabilidade do Estado. A sociedade civil pode e deve colaborar com o Estado, a partir de suas experiências, introduzindo de forma negociada soluções para os problemas sociais.

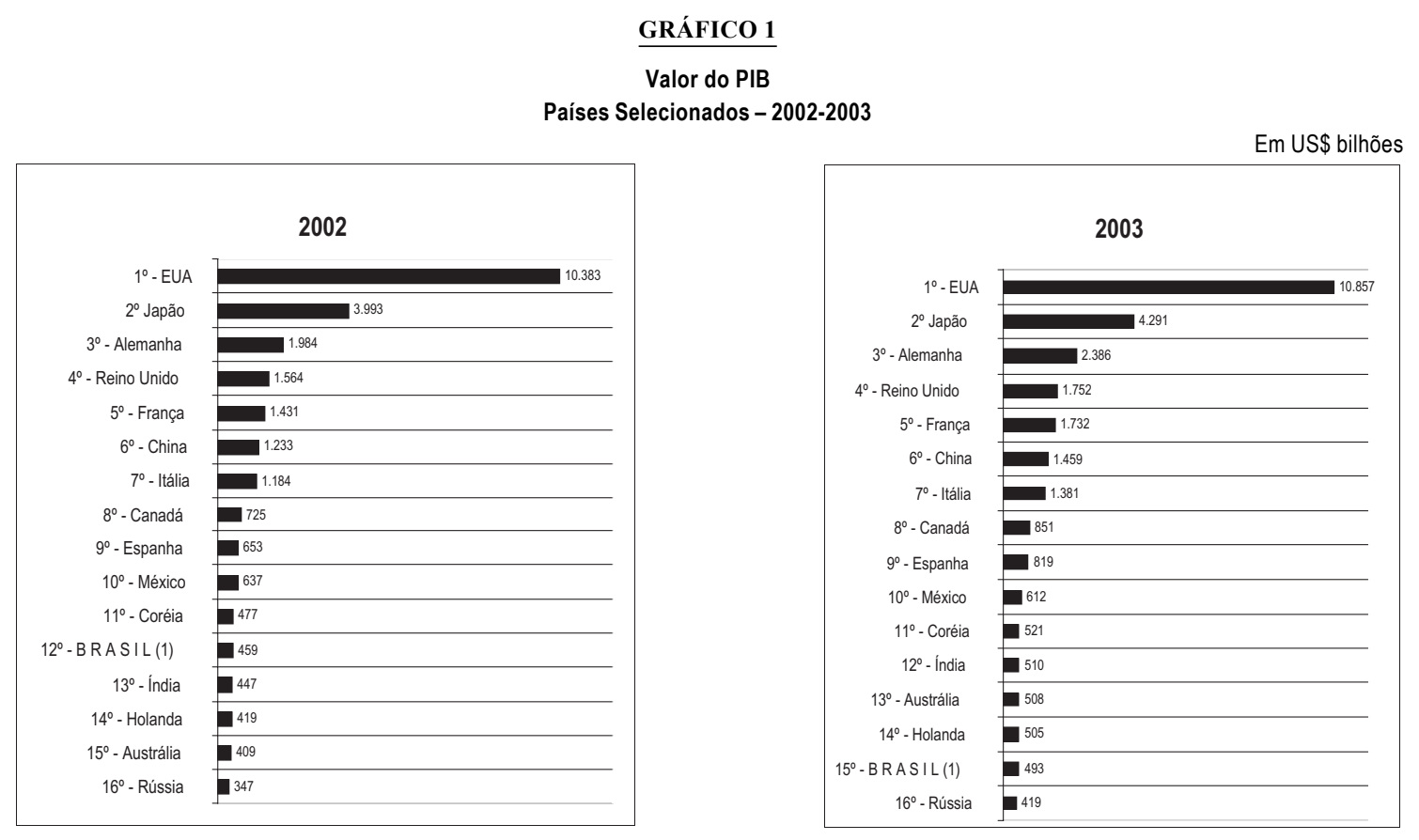

Fonte: Global Invest, com dados do IBGE, Banco Central, Organização para a Cooperação e o Desenvolvimento Econômico - OCDE, FMI e bancos centrais. (1) Estimativa. 
Por sua vez, representantes do empresariado vinculado à filosofia da responsabilidade social empresarial compreendem que a agenda política do país deve ser pautada pela parceria entre o Estado, a sociedade civil e as empresas. Nas décadas anteriores a 80 , a agenda política dos Estados Nacionais pautava-se, entre outros temas, na contraposição empresas e mercado versus Estado. Hoje essa contraposição perdeu o sentido. A agenda política de um país deve ser pautada pela parceria entre o Estado, a sociedade civil organizada e as empresas. O investimento social privado se faz necessário devido aos inúmeros problemas sociais. Entretanto, vale lembrar que o papel social da empresa não se resume a este investimento. É fruto também de uma relação ética da empresa com seus funcionários, com seus fornecedores, com o governo, com seus clientes (que são denominados stakeholders) e com o meio ambiente (MATTAR, 1999).

Segundo a Amcham $^{7}$ (2003) as empresas socialmente responsáveis têm entre seus objetivos contribuir com a implementação das políticas públicas. Cabe às empresas utilizar seu poder de mobilização para atuar como agentes e parceiros do desenvolvimento social.

Conhecer os programas governamentais é um passo fundamental nesse processo, a partir do qual a empresa pode identificar oportunidades de inserção, por meio da disponibilização de recursos, da capacitação de agentes e da mobilização de outras organizações e demais stakeholders, entre outras iniciativas.

Ao atuar alinhada às políticas públicas, a empresa pode contribuir para o fortalecimento do papel do Estado, [...] na busca de soluções efetivas para os problemas sociais existentes (AMCHAM, 2003, p. 36).

É fundamental destacar que a Amcham-SP em 1982 instituiu o Prêmio ECO (Prêmio de Contribuição Empresarial à Comunidade). Perfilando o caminho da responsabilidade social empresarial, o Prêmio ECO vem exercendo forte influência ao reconhecer e incentivar empresas que apóiam projetos sociais por ser

uma iniciativa de caráter exclusivamente sociocultural e sem fins lucrativos, que visa a distinguir e homenagear anualmente alguns entre os principais programas sociais voltados para o bem-estar social e para o desenvolvimento do país, desenvolvidos por empresas, fundações e instituições empresariais localizadas no Brasil (AMCHAM, 2003, p. 11).

São premiados projetos que se destacam nas seguintes categorias: educação, cultura, meio ambiente, saúde e participação comunitária.
Desde sua criação até 2003, a Amcham-SP, mediante o Prêmio ECO, obteve inscrição de 1.729 projetos, representados por 1.372 empresas, sendo que, do total de projetos inscritos, foram premiados 123 , nos quais foram investidos mais de US\$ 2,8 bilhões. Destaque-se que criança e adolescente são os principais públicos beneficiados pelos projetos vencedores nos 21 anos de existência do Prêmio ECO. Há uma tendência do empresariado em possuir como público-alvo a criança e o adolescente, investindo em projetos sociais na área da educação (ensino fundamental e profissionalizante). Por exemplo, $85,4 \%$ das associadas do Gife desenvolvem e/ou incentivam projetos nessa área (GIFE, 2001). Considera-se que a estratégia desse tipo de investimento tem como uma de suas metas capacitar o elemento humano, que poderá permitir ao empresariado a possibilidade de buscar, no mercado de trabalho, o profissional que apresente o novo perfil que atenda às vantagens competitivas dos mercados voltados às economias abertas.

Assim como o Instituto Ethos, o Gife e a Amcham-SP, ao incentivar e divulgar suas experiências bem-sucedidas, podem servir de base para a elaboração de políticas sociais, uma vez que disseminam a efetividade dos programas sociais (relação eficiência e eficácia), a influência do programa na qualidade de vida do usuário, de seus familiares e na comunidade em geral, os impactos que os referidos programas causam na comunidade onde se realizam, inclusive nas próprias fundações empresariais, a percepção gradativa, por parte do usuário, da sua condição de cidadão, e a formação de uma imagem institucional, destacando o interesse da organização pelas questões sociais, éticas e políticas, o que, inclusive, constitui elemento de vantagem competitiva diante do mercado.

Todavia, como visto anteriormente, os investimentos realizados pela responsabilidade social empresarial atingem parcelas da população brasileira que são selecionadas para ingressarem nos seus projetos mediante critérios estabelecidos pelas próprias fundações, institutos empresariais e organizações parceiras. Tais critérios não privilegiam necessariamente a população mais necessitada dos serviços de saúde, de moradia ou mesmo de alimentação (combate à fome).

É um fato que o volume dos investimentos empresariais não conseguirão assumir os mínimos sociais. Diante do Estado neoliberal da limitação dos gastos com as Políticas Sociais, considerando os dados apresentados sobre as desigualdades sociais no país, a situação se complexifica.

Esta é uma questão contraditória que coloca em cheque a filosofia e os princípios da responsabilidade social empresarial, pois os serviços sociais direcionam-se para 
uma camada de cidadãos definida com base em critérios diferentes daqueles da universalidade de direitos.

Todavia, diante das implicações que a questão social tem colocado ao Estado, ao mercado e à sociedade civil, entende-se que, embora contraditórios (pois o empresariado possui seus próprios interesses, tais como vantagem competitiva, visibilidade nos negócios e divulgação de imagem), os investimentos sociais empresariais revelam um compromisso público do empresariado no enfrentamento das desigualdades sociais, buscando colaborar com o desenvolvimento social sustentável.

Certamente ao mencionar o crescente aumento dos investimentos empresariais em projetos sociais, é preciso que a nossa análise desvele o real sentido dessa prática, porque se apresenta como algo novo. Vive-se, neste país, onde as disparidades sociais tornaram-se um desafio não só para o Estado, mas para os mais variados segmentos da sociedade civil. Há de se observar que, para além dos negócios da empresa (razão fundante da existência da mesma), há algo novo na atitude de parcela do empresariado (RICO, 2001, p. 28).

Se é evidente que os investimentos sociais empresariais vêm ocorrendo no sentido da rearticulação do próprio capital, é certo igualmente que segmentos da burguesia nacional "sem fronteiras" e/ou internacional, porém situados geograficamente no Brasil, vêm apresentando uma postura diferenciada, na qual se observa um perfil mais arrojado no enfrentamento da crise social, concretizado na implementação e/ou financiamento de projetos sociais, parcerias que são estabelecidas com outras organizações da sociedade civil e mesmo com o Estado. Um bom exemplo é o Programa Fome Zero, lançado em 2003 pelo governo federal, que tem por objetivo estimular a organização da sociedade para que ela faça a sua parte na formulação, execução e acompanhamento de políticas de segurança alimentar e nutricional. O Conselho de Segurança Alimentar e Nutricional - Consea é formado pelo poder público, por representantes da sociedade civil organizada e por representantes de associações empresariais. O Instituto Ethos, por exemplo, elaborou manuais para orientar empresários, professores e demais membros da comunidade acadêmica, quanto às formas de colaboração e de inserção no programa. Os referidos manuais são: "Como as empresas podem apoiar e participar do combate à fome"; "Segurança alimentar: a contribuição das universidades"; e "O que as empresas podem fazer pela erradicação da pobreza" ${ }^{8}$

Se enfrentar desigualdades sociais depende de decisões em nível de políticas públicas e sociais, cuja elaboração e implementação é uma responsabilidade prioritária do Es- tado, diante de uma crise social sem precedentes no nosso país torna-se praticamente imprescindível que segmentos da sociedade civil, empresariado, associações de classe, entidades assistenciais e filantrópicas realizem parcerias com o setor governamental como uma possibilidade para este enfrentamento. Nesse sentido, a responsabilidade social empresarial representa, contraditoriamente, um elemento novo na dinâmica do desenvolvimento do capital e, ao mesmo tempo, uma possibilidade de representação cívica nas esferas pública e privada.

A empresa socialmente responsável conseguiu uma grande vantagem competitiva em relação às demais, uma vez que vai assimilando o papel de co-responsabilidade no enfrentamento da desigualdade e da exclusão social. Conclui-se que, diante da necessidade de rearticulação do próprio capital, existe hoje, no Brasil, um segmento empresarial em condições objetivas de somar seus esforços a outros parceiros na luta pelo desenvolvimento econômico, social, viável e ambientalmente sustentável.

\section{NOTAS}

1. O Instituto Ethos de Empresas e Responsabilidade Social é uma associação de empresas de todo tamanho e setor interessadas em desenvolver suas atividades de forma socialmente responsável num permanente processo de avaliação e aperfeiçoamento. Este foi criado em 1998, com a missão de promover e disseminar práticas empresariais socialmente responsáveis contribuindo para que empresas e sociedade, alcancem um desenvolvimento sustentável em seus aspectos econômico, social e ambiental.

2. O processo de globalização da economia é fundamentado na internacionalização dos meios produtivos com ênfase na integração dos mercados, influindo diretamente nas questões relacionadas ao mundo do trabalho. Segundo Ianni (1995, p. 47) "a globalização intensificou e generalizou o processo de dispersão geográfica da produção ou das forças produtivas, compreendendo o capital, a tecnologia, a força de trabalho, a divisão do trabalho social, o planejamento e o mercado".

3. "Investimento social privado é o uso planejado, monitorado e voluntário de recursos privados - provenientes de pessoas físicas ou jurídicas - em projetos de interesse público. Incluem-se no universo do investimento social privado as ações sociais protagonizadas por empresas, fundações e institutos de origem empresarial ou instituídos por famílias ou indivíduos" (GIFE, 2001, p. 11).

4. "O Gife atua fortemente na busca de soluções para a superação das desigualdades sociais brasileiras, tendo como objetivo estratégico influenciar as políticas públicas por meio de parcerias e do compartilhamento de idéias, ações e aprendizados com o Estado e outras organizações. Para alcançar esse objetivo, o Gife baseia seu trabalho no fortalecimento político-institucional, na capacitação e no apoio à atuação estratégica de seus associados e de institutos e fundações, especialmente de origem empresarial.

Nestes quase dez anos de atuação o Gife se consolidou como uma referência no Brasil sobre investimento social privado e vem contribuindo para a criação de outras associações similares na América Latina" (GIFE, 2004a).

5. É importante afirmar que esse segmento do empresariado não pode ser "descolado" da sua classe social de origem. Pertencente à classe 
burguesa vem apresentando características que o distinguem da mesma. Poderíamos falar na constituição de valores civilizacional, o que constitui um amadurecimento de setores da classe capitalista. A constituição desses padrões civilizacionais pelo empresariado ou por meio de pactos entre grupos empresariais possuem, na verdade, o interesse em criar melhores condições de ação para o próprio capital.

6. Tais informações foram retiradas do "Atlas da Exclusão Social - Os Ricos no Brasil", com base nas informações dos Censos de 1980 e 2000 e da Pesquisa Nacional por Amostra de Domicílios - PNAD.

7. Fundada em 1919, a Câmara Americana de Comércio de São Paulo - Amcham-SP é a segunda maior Câmara Americana de Comércio do mundo e a maior fora dos Estados Unidos. Sua missão é "servir seus associados, influenciando construtivamente políticas públicas no Brasil e nos Estados Unidos e promovendo o comércio, o investimento e a cidadania empresarial.

A Amcham-SP é uma organização privada e sem fins lucrativos que congrega cerca de 5.560 sócios, entre pequenas, médias e grandes empresas, que atuam nas mais diversas áreas da economia e empregam 1,6 milhão de trabalhadores. Uma das prioridades da AmchamSP é mobilizar, incentivar e abrir espaço para discussão e viabilização de ações de empresas no campo social" (AMCHAM, 2003, p. 10).

8. Estes manuais estão disponibilizados no site do Instituto Ethos (http://www.ethos.org.br).

\section{REFERÊNCIAS BIBLIOGRÁFICAS}

BOSCHI, R.R.; DINIZ, E. Empresários e constituinte: continuidade e rupturas no modelo de desenvolvimento capitalista no Brasil. In: CAMARGO, A.; DINIZ, E. (Org.). Continuidade e mudança no Brasil na Nova República. São Paulo: Vértice: Revista dos Tribunais, 1989.

CIEE - Centro de Integração Empresa-Escola. Revista Agitação, Brasília, ano VII, v. II, n. 39, maio/jun. 2001.

Revista Agitação, Brasília, ano V, n. 30, out./dez. 1999.

DOWBOR,L. Gestão social e transformação da sociedade. In: DOWBOR, L.; KILSZTAJN, S. (Org.). Economia social no Brasil. São Paulo: Ed. Senac, 2001. p. 17-41.

FERNANDES, R.C. Terceiro setor - desenvolvimento social sustentável. Rio de Janeiro: Paz e Terra: Gife,1997.

FOLHA DE S.PAULO, São Paulo, 2 abr. 2004, cad. 6, p.1.

, São Paulo, 1 abr. 2004, Folha Dinheiro, p.B3.

São Paulo, 25 mar. 2004, Folha Dinheiro, p.B4.

GIFE. Grupo de Institutos Fundações e Empresas. Sobre o Gife. São Paulo: 2004a. Disponível em:

$<$ http://www.gife.org.br/oqueegife.php>. Acesso em: 30/03/2004.

Grupo de Institutos Fundações e Empresas. Associados. São Paulo: 2004b. Disponível em: <http://www.gife.org.br/ associados_busca.php?tipo_b=1>. Acesso em 30/03/20004.

Grupo e Institutos Fundações e Empresas. Investimento Social Privado no Brasil: perfil e catálogo das associados Gife. São Paulo: 2001.

GUIMARÃES, S.D. Programa de Educação Continuada: uma experiência de parceria entre uma ONG e a Secretaria de Estado da Educação - SEE/SP. In: RICO, E.M.; RAICHELIS, R. (Org.). Gestão Social: uma questão em debate. São Paulo: EDUC/IEE, 1999. p. 221-231.

IANNI, O. A Internacionalização do Capital - Teorias da Globalização. Rio de Janeiro: Civilização Brasileira, 1995.

INSTITUTO ETHOS. Responsabilidade Social das Empresas: a contribuição das universidades. São Paulo: Peirópolis: 2003a. v. II.
Responsabilidade Empresarial para Micro e Pequenas Empresas. Passo a Passo. São Paulo: Instituto ETHOS/Sebrae, out. 2003 b.

Responsabilidade Social das Empresas: a contribuição das universidades. São Paulo: Peirópolis: 2002. v. I.

Responsabilidade Social nas Empresas. Primeiros Passos. 1. ed. São Paulo: set. 1998.

IPEA - Instituto de Pesquisa Econômica Aplicada. A iniciativa privada e o espírito público - Resultados nacionais. Brasília: 2002. Disponível em:

$<$ http://www.ipea.gov.br/asocial/iniciativa-resultadosnacionais.htm>. Acesso em: 6 out. 2002.

MATTAR, H. Rede Gife - Boletim Informativo Semanal. São Paulo. ano III, n. 110, 13 set. 1999.

MENEGASSO, M.E. Responsabilidade social das empresas: um desafio para o Serviço Social. São Paulo, 2001. (Texto apostilado).

MIFANO, G. A crise mundial de confiança nas empresas: uma questão de Responsabilidade Social. Disponível em:

$<$ http://www.ethos.org.br/docs/conceito_praticas/publicações/ Debates/a_crise mundial.ppt>. Acesso em: 28/08/2003. (Evento da Bolsa de Valores de São Paulo, 14/08/2002).

NASSER, A.C.A. Sair para o mundo - trabalho, família e lazer: relação e representação na vida dos excluídos. In: DOWBOR, L.; KILSZTAJN, S. (Org.). Economia Social no Brasil. São Paulo: Ed. Senac-SP, 2001. p.305-314.

PAES, A. A Responsabilidade Social Empresarial (RSE): espaço de intervenção profissional do Serviço Social. 2003. Trabalho de Conclusão de Curso. Faculdade de Serviço Social da PUC-SP, São Paulo, 2003.

RAMOS, C. Selo Empresa Cidadã. Agitação, Brasília, CIEE, ano X, n.54, nov./dez. 2003.

RICO, E.M. Memorial para Concurso de Preenchimento de Vaga de Professor Assistente-Doutor. Faculdade de Serviço Social - PUCSP, São Paulo, fev. 2002a.

Gestão Social e Exclusão: o paradoxo do desenvolvimento econômico, viável, social e ambientalmente sustentável. Cadernos de Serviço Social. Faculdade de Serviço Social. PUC-Campinas. Ano XI, n. 20/21, p. 7-27, jan./dez. 2002b.

Filantropia Empresarial e a Gestão de Projetos Sociais. 2001. 159 p. Tese (Doutorado). Estudos de Pós-Graduação em Ciências Sociais da PUC-SP, São Paulo, 2001.

O empresariado, a filantropia e a questão social. São Paulo em Perspectiva, São Paulo, Fundação Seade, v. 11, n. 4, p. 6069, out.-dez. 1997.

ROCHA, S. Alguns consensos sobre a pobreza no Brasil. In: DOWBOR, L.; KILSZTAJN, S. (Org.). Economia Social no Brasil. São Paulo: Ed. Senac-SP, 2001. p. 71-88.

SENNA, V. O caminho dos caminhos. 10 mandamentos para a carreira. Folha de S.Paulo, São Paulo, 22 abr. 2001. Folha Empregos. Edição Especial, p.11.

SPOSATI, A.O. et al. A assistência na trajetória das Políticas Sociais Brasileiras. São Paulo: Cortez, 1985.

VASSALO, C. Agenda para o futuro. Exame, São Paulo, p. 64-79, 13 jan. 1999.

Elizabeth de Melo Rico: Professora da Faculdade de Serviço Social da PUC-SP, Pesquisadora do Núcleo de Estudos Avançados do Terceiro Setor do Programa de Pós-Graduação em Administração da PUC-SP (bmbrico@uol.com.br). 